\title{
Grain refinement of pure Ti during plastic deformation
}

\author{
S. Wu ${ }^{\mathrm{a}, *}$, K. Fan ${ }^{\mathrm{a}}$, P. Jiang ${ }^{\mathrm{b}}$, S. Chen ${ }^{\mathrm{b}}$ \\ a The High School Affiliated to Renmin University of China, 37 Zhongguancun Street, Beijing 100080, China \\ ${ }^{\mathrm{b}}$ State Key Laboratory of Nonlinear Mechanics, Institute of Mechanics, CAS, Beijing 100190, China
}

\section{A R T I C L E I N F O}

\section{Article history:}

Received 10 April 2010

Received in revised form 22 June 2010

Accepted 28 June 2010

\section{Keywords:}

Nanocrystalline

Dynamic recrystallization

Grain refinement

Surface mechanical attrition treatment

\begin{abstract}
A B S T R A C T
The mechanism of grain refinement was studied in titanium subjected to high-rate surface mechanical attrition treatment. By cross-sectional transmission electron microscopy, the deformation structures were systematically characterized in a nanocrystalline (NC) layer of the treated surface which exhibits a grain size gradient. The microstructural evolution with increasing strain involves (1) the formation of slip bands with dislocation-free cells in their interiors, (2) nucleation and migration of high-angle grain boundaries at cell boundaries consisting of high-density tangled dislocations, leading to the formation of submicrosized grains inside the slip bands, followed by (3) the formation of subgrains and dislocation cells inside the submicrosized grains with increasing misorientations, which finally become NC grains. The mechanism of grain refinement was interpreted in terms of the classical migration dynamic recrystallization (DRX) and continuous rotation DRX, respectively, leading to submicrosized and NC grains with increasing strains at high strain rates. The cooperative grain boundary sliding is active at high strain rate, by the presence of arrays of coplanar grain boundaries.
\end{abstract}

(C) 2010 Elsevier B.V. All rights reserved.

\section{Introduction}

One efficient technical route to strengthen metals is microstructural refinement by plastic deformation. Using severe plastic deformation methods such as equal channel angular pressing and high pressure torsion, the structural length scales of most metals can be easily reduced into the sub-micrometer range [1-6]. By contrast, the exploratory friction-stir experiment [7] and surface mechanical attrition treatment (SMAT) [8-11] may effectively reduce the structural length scale to $10-50 \mathrm{~nm}$. Analysis of the active deformation mechanisms is a crucial step in clarifying the hardening behavior associated with grain refinement [1,2,7-15].

Titanium and its alloys have increasingly wide applications in aerospace, automotive, power generation (turbine engine) and biomedical areas. Reduction in grain size significantly increases the strength and hence extends applications that requires reliable performance. The grain refinement mechanisms of $\mathrm{Ti}$ is, however, still unclear due to lack of systematic observations of deformation structures [16-23]. For example, a dynamic recrystallization (DRX) process is suggested to account for the formation of submicrosized grains [16-18]. The detailed mechanism as to how the recrystallized grains nucleate and grow is not well understood. Further evolution with strain from submicrosized grains to NC grains has not been reported in literature.

\footnotetext{
* Corresponding author. Fax: +86 1062561284.

E-mail address: wu_HSARU@hotmail.com (S. Wu).
}

The present work aims at studying the grain refinement mechanism in Ti by plastic deformation to ultrahigh strains. The special attention is paid to the details of DRX process so as to clarify the formation of submicrosized and NC grains. Deformation twinning is not included in the present study due to the fact that deformation twinning occurs first at low strains and that dislocation slip takes over at high strains and is responsible for the grain refinement [16].

\section{Experimental procedure}

A commercial purity titanium sheet was used in this study. The chemical composition is (wt.\%) $0.007 \mathrm{C}, 0.0013 \mathrm{H}, 0.08 \mathrm{O}, 0.030 \mathrm{Fe}$, and Bal. Ti. The starting sample, $1 \mathrm{~mm}$ thick and $80 \mathrm{~mm}$ in diameter, was annealed to have equiaxed grains with a mean grain size of $40 \mu \mathrm{m}$.

The SMAT set-up and procedure have been described in detail elsewhere $[8,9]$. The technique is based on the vibration of spherical shots using high-energy ultrasound. Stainless steel shots were placed at the bottom of a cylinder-shaped vacuum chamber that was vibrated by a generator, with which the shots were resonated. Because of the high vibration frequency of the system, the sample surface was peened by a large number of shots. As a consequence, repeated multidirectional peening at high strain rates produces severe plastic deformation in the surface layer. In this work, the sample was treated by shots of $4 \mathrm{~mm}$ in diameter at a frequency of $20 \mathrm{kHz}$ for $15 \mathrm{~min}$ at room temperature. Note that both the imposed strain and the strain rate have a gradient distribution and the approximate strain rate is $10^{2-3} \mathrm{~s}^{-1}$ near the treated surface. 
TEM observation was carried out to clarify the deformation structures in the treated layer. The grain size gradient in the layer appears due to a gradient in the imposed strains and strain rates along the depth, from very large (top surface layer) to zero (strainfree matrix) during the SMAT process $[8,9]$. Hence, deformation structures of various length scales can be obtained in the deformed surface layer along the depth from the treated surface to the strain-free matrix, i.e. from nano-sized grains to submicrosized and microsized crystallites. As such, the evidence for grain refinement at different strains and strain rates can be obtained. The crosssectional thin foils for TEM observations were prepared by means of standard sample preparation protocols such as cutting, grinding, dimpling and a final ion thinning at a low temperature.

\section{Experimental results}

\subsection{Formation of slip bands and dislocation-free cells}

Fig. 1(a) is a TEM micrograph showing the sharply defined slip bands at low strains ( $\sim 100 \mu \mathrm{m}$ deep below the top surface). The slip bands consist of several elongated subgrains of about several microns in length. The selected area electron diffraction (SAED) pattern (inset) shows some small arcs, indicating small misorientations among these subgrains. The slip bands, aligned along the [ $\left.1 \begin{array}{lll}1 & 2 & 0\end{array}\right]$ direction, result from dislocation slip on the basal planes. In particular, the slip bands are observed to occupy $\sim 80 \%$ of the area observed, indicating the dominant role of slipping at low strains. The dislocation density in the slip bands increases with strain, as shown in SB1 of Fig. 1(b). The source of dislocations seems to lie mainly at the subgrain boundary as indicated by arrows. Later on and with increasing strain, the cells start to appear in the interior of the slip bands with increasing dislocation density, as shown in Fig. 1(c). The interior of the cells is nearly dislocation-free, e.g. the cell marked by A; whereas the boundary of cells consists of tangled dislocations of high density.

\subsection{Migration dynamic recrystallization ( $m-D R X)$}

Fig. 2(a) shows the presence of a segment of high-angle grain boundary (HAGB) $(\sim 80 \mu \mathrm{m}$ deep below the top surface of the specimen). The HAGB is of sharp contrast as indicated by an arrow. The HAGB originates from the cell boundary, i.e. tangled area of high density dislocations and increases its length with strain. It is interesting to note that the HAGB seems to migrate along the arrow direction, i.e. from the cell interior to the area of high-density dislocation, and the area that the boundary passes through is nearly dislocation-free. In Fig. 2(b), the more parts of HAGBs form as indicated by several arrows and hence, the grain contour becomes visible due to the GB migration. The interior of the immature grains, labeled A and B, respectively, is of few dislocations, in contrast to nearby areas of high-density dislocations. Therefore, the classical DRX, viz., migration DRX (m-DRX) mechanism operates [24-27], which is characterized by the movement of preexisting HAGBs through the deformed microstructure, leaving a strain free region in their wake.

Fig. 2(c) shows one completely recrystallized equiaxed grain, labeled $A$, in the slip bands. Clearly, this submicrosized grain is dislocation-free. Fig. 2(d) shows the formation of submicrosized grains in the interior of the slip bands due to m-DRX at this stage of strain ( $\sim 60 \mu \mathrm{m}$ deep below the top surface). Many grains become nearly equal-axed, with sharp grain boundaries as indicated by several arrows. Such features are normal after m-DRX.
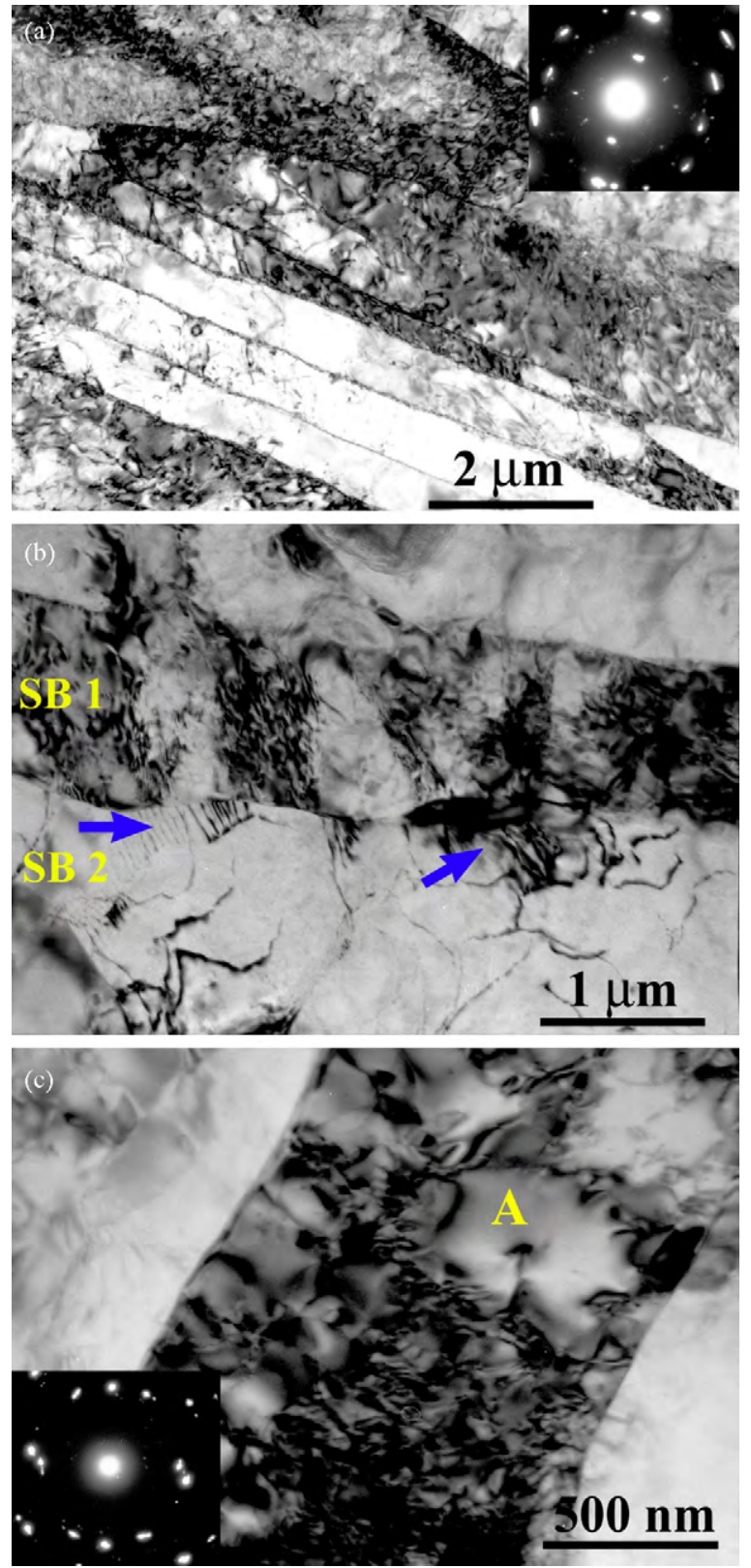

Fig. 1. TEM micrographs showing the deformation structure at a low strain leve ( $\sim 120 \mu \mathrm{m}$ deep away from the treated surface). (a) Slip bands of elongated subgrains. Inset is the SAED pattern covering several slip bands, indicating the low-angle boundaries between subgrains. (b) Formation of dislocations in slip bands. Note the dislocation source mainly at boundaries between subgrains as indicated by arrows. (c) Formation of dislocation-free cells in the area of tangled dislocations of high density. One cell is labeled by A. Inset is the SAED pattern covering one slip band.

\subsection{Rotation dynamic recrystallization ( $r-D R X)$}

The above recrystallized grains may again accumulate dislocations of high density in their interiors due to repetitive deformation as shown in Fig. 3(a). The non-uniformly, tangled dislocations of high density are visible in this figure. With increasing strain, the more refined deformation structure appears, mostly having sizes smaller than $100 \mathrm{~nm}$, as shown in Fig. 3(b). It is interesting to note that the SAED pattern still consists of small arcs, suggesting small misorientations. This indicates the presence of subgrains with lowangle grain boundaries. Fig. 3(c) shows the formation of NC grains with well-defined grain boundaries ( $\sim 40 \mu \mathrm{m}$ deep below the top surface). In comparison with the diffused feature of Fig. 3(b), the 

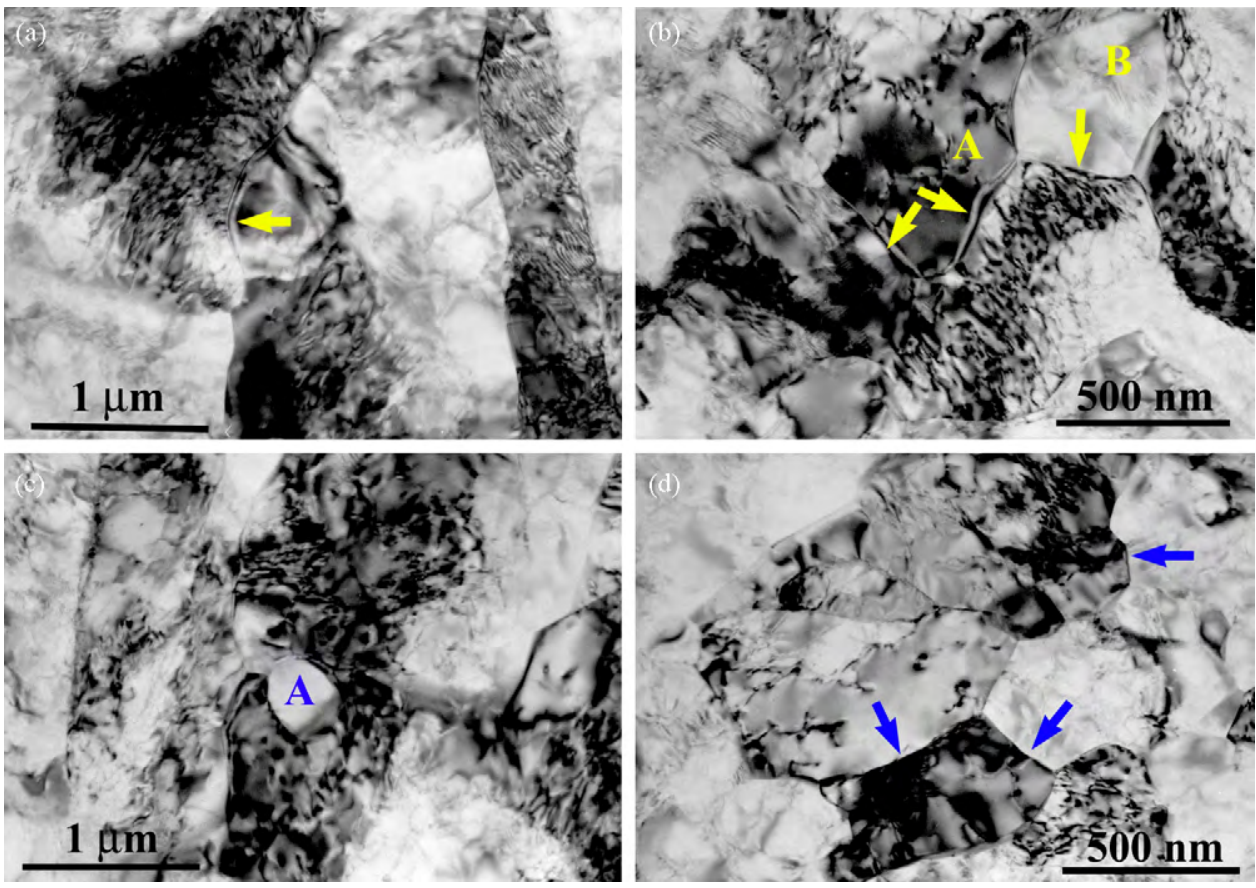

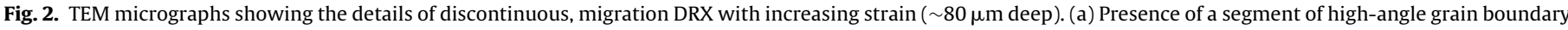

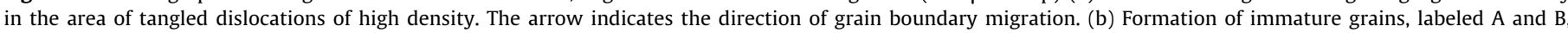

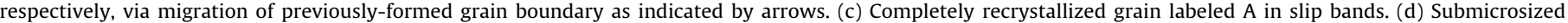
structure after migration DRX.

grains are now much easier to resolve. Inset of Fig. 3(c) is the SAED pattern. A set of distinctive continuous rings is observed instead of scattered spots or arcs, indicating the existence of highly misoriented grains. The grain sizes span a range, but are definitely in the nanometer regime. Moreover, the crystallites have sizes similar to those in Fig. 3(b). The average grain size was measured using the linear intercept method to be $58 \mathrm{~nm}$ based on statistics over 180 grains. Therefore, from these observations we can infer that the continuous, rotation DRX (r-DRX) operates [24,25,28]. This mechanism involves the gradual rotation of subgrains with increased plastic strain. Eventually the misorientation between neighboring subgrains is sufficiently large that the subboundaries are turned into HAGBs.

One peculiar microstructural feature is shown in Fig. 4. The individual cells have gone through a large shear along a single slip plane, by the presence of a microscopic shear plane extending over several cell boundaries (indicated by arrows). This points to grain boundary sliding that often occurs during superplasticity deformation at high temperatures. This feature was typically observed quite frequently in submicrosized grains especially at high strain rates [29].

\section{Discussion}

Based on the evolution of the deformation structure described above, it is assumed that two DRX processes play important roles in the process of grain refinement of Ti during plastic deformation, leading to the formation of submicrosized and NC grains, respectively.

For the m-DRX, as shown in Fig. 2(a), the cell boundary and other areas as well with high population dislocations are probably the prerequisite for direct nucleation of a segment of HAGB. Hence, the m-DRX, normally a high-temperature phenomenon, can be triggered at low homologous temperatures only if a very large accumulated strain (or a critical stored energy) is reached. The initial size for the HAGB formation may be only a few nanometers, but the segment of HAGB may lengthen and migrate rapidly with increasing strain. According to our TEM observations, the m-DRX seems to initiate when a critical strain, $\varepsilon_{C r i}$, is reached. In other words, in this case, the critical strain is translated a certain depth of the treated layer. Barnett proposed two dimensionless terms to evaluate the critical condition for the onset of m-DRX [26], i.e. $\Theta=M G^{2} / \gamma \dot{\varepsilon}^{2}$ and $\Omega=(\sigma / G)^{3}$, where $M$ is the boundary mobility during recrystallization, $G$ is the shear modulus, $\gamma$ is the surface energy per area of grain boundary, $\dot{\varepsilon}$ is the strain rate, $\sigma$ is the flow stress. The former reflects the roles of boundary mobility $(M)$ and the time (through $\dot{\varepsilon})$ available for the reaction and the latter reflects the stored energy driving it (through $\sigma$ ) [26]. During m-DRX, the dynamically recrystallized grain size, $D$, is determined by a dynamic balance between kinetics of nucleation and kinetics of grain growth. $D$ is inversely proportional to the strain rate, i.e., $D=c(M G \theta / \dot{\varepsilon})(\sigma / G)^{2}$, where $c$ is a constant, $\theta$ is the mean subgrain boundary misorientation [26]. Hence, high strain rate not only promotes m-DRX, but also reduces the steady-state grain size.

On the other hand, the recrystallized submicrosized grains will experience further straining. As such, high-density dislocations are generated (Fig. 3a), which evolve into cells and subgrains (Fig. 3b). Approaching to the top surface during the SMAT process, both strain rates and strains increase significantly $[8,9]$. The increase in strain rate will increase dislocation density at a given level of strain $[30,31]$. High strain rates promote the rotation of subgrains and dislocation cells as well. Therefore, the continuous r-DRX begins to operate, involving the gradual rotation of subgrains and cells. The higher strain rates raise the misorientation across adjacent substructures up to a higher value than lower strain rate [22]. Hence, it is reasonable that the subgrains act as precursors of DRX nuclei. As the HAGBs are formed by progressive increase of misorientation angles, eventually the NC grains are similar in size to that of the subgrains $[28,32]$. This is indeed the case from TEM observations. The NC grains in Fig. 3(c) have sizes comparable to those of the subgrains in Fig. 3(b). These grains have clear boundaries and are equiaxed. This microstructure is similar to those observed in $\mathrm{Ti}$ [33] and stainless steel [28]. It has been attributed to the r-DRX 

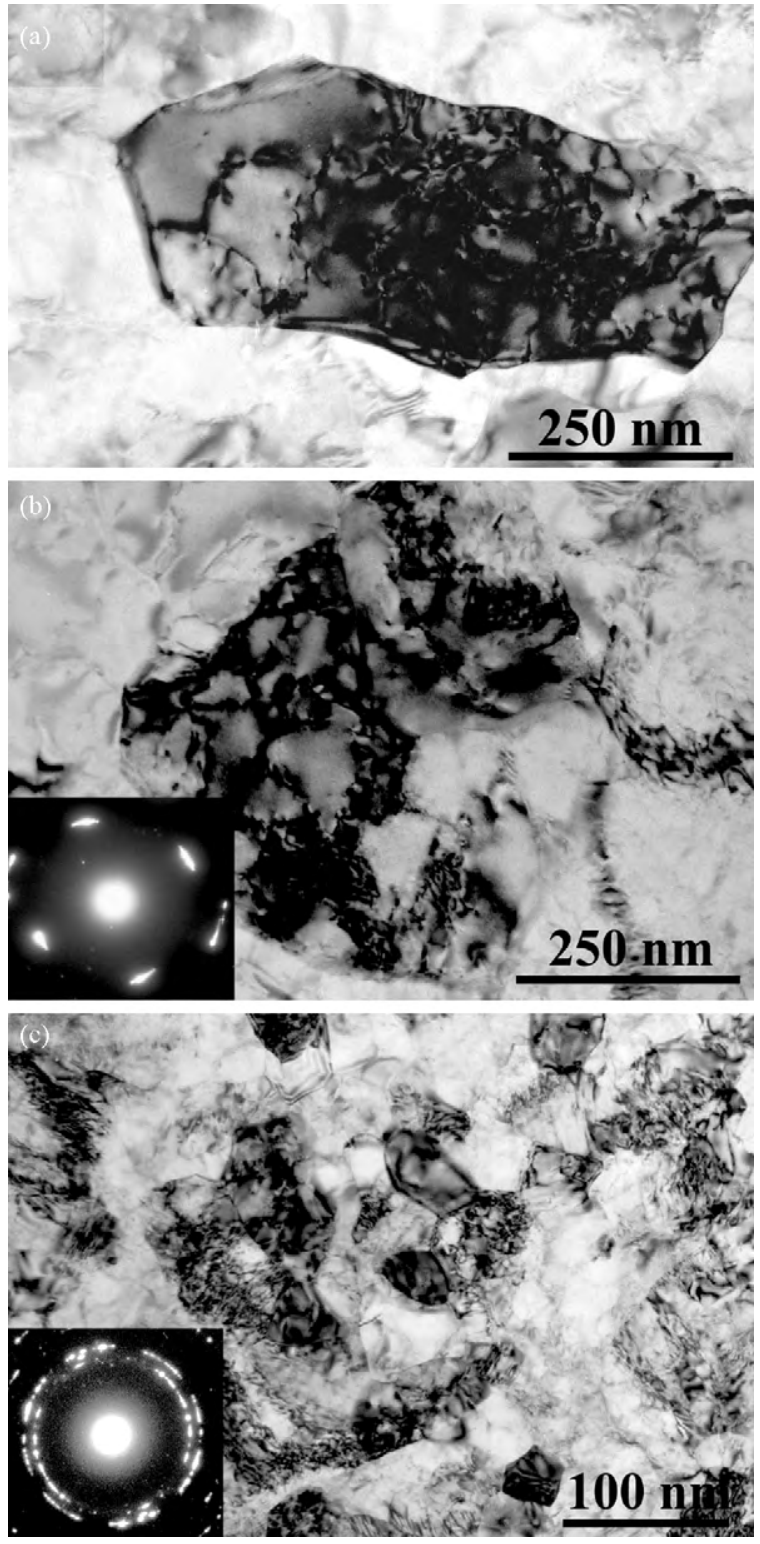

Fig. 3. TEM micrographs showing the details of continuous, rotation DRX at a high strain level ( $\sim 60 \mu \mathrm{m}$ deep). (a) Tangled dislocations of high density in recrystallized grains. (b) Subgrains and cells. Inset is the SAED pattern. (c) Nanocrystalline grains of high-angle boundaries. Inst is the SAED pattern.

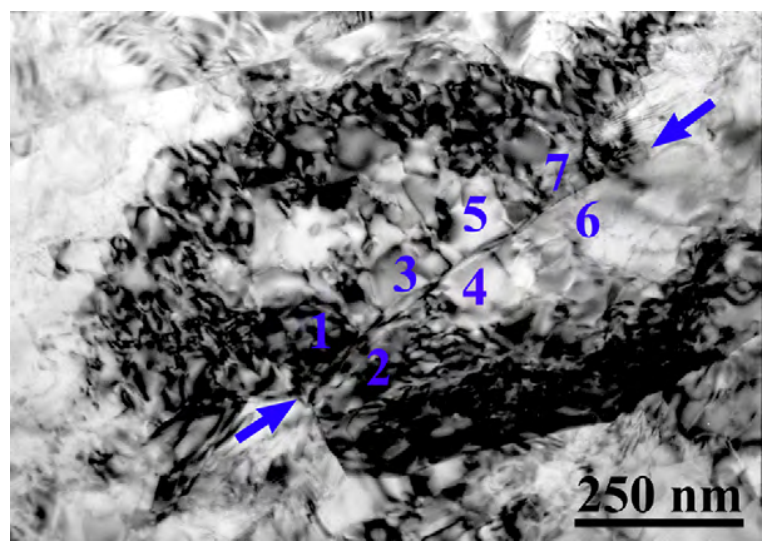

Fig. 4. TEM micrograph showing the alignment of boundaries of 7 cells with formation of a microscopic shear plane. mechanism. Meyers et al. [28] observed and modeled the process of r-DRX in adiabatic shear localization in a stainless steel. Also, TEM examinations clearly indicate the importance of grain boundary rotation in microstructural evolution. Hence, r-DRX operates in the final stage of grain refinement process, leading to the NC formation.

Remarkably, as shown in Fig. 4, the presence of microscopic glide planes in some grains may be regarded as clear evidence for grain boundary sliding at room temperature deformation. It indicates that high strain rate promotes the microscopic boundary sliding [29], contributing to the deformation, similar to superplastic deformation which is usually observed at high temperatures.

\section{Conclusion}

The grain refinement behavior was studied in Ti during SMAT. The evolution of deformation structure allows detailed investigation of the DRX phenomena upon deformation. Strain and strain rate are found to affect the grain refinement processes. In summary, the experimental results and their interpretation allow us to come to the following conclusions:

(1) The deformation structures form by the sequence of slip bands with elongated subgrains, tangled dislocations of high density and cell structures, respectively, at low strains.

(2) By the nucleation and migration of high-angle grain boundary inside slip bands with increasing strain, the classical, migration dynamic recrystallization starts to operate at a critical strain, leading to the formation of submicrosized grains.

(3) Upon further plastic deformation, the recrystallized submicrosized grains lead to further breakup by the formation of subgrains. The nanocrystallites form mainly due to a continuous, rotation dynamic recrystallization mechanism. That is, by the progressive increase of GB misorientations at large strain at high strain rate.

(4) The formation of arrays of coplanar grain boundaries confirms a deformation mechanism of cooperative grain boundary sliding.

\section{Acknowledgements}

This research received backing from NSF of China Grant No. 10721202 and 973 Project Grant Nos. 2010CB631004.

\section{References}

[1] T.G. Langdon, Mater. Sci. Eng. A Sp. Iss. 462 (2007) 3-11.

[2] R.Z. Valiev, T.G. Langdon, Prog. Mater. Sci. 51 (2006) 881-981.

[3] Y.T. Zhu, T.G. Langdon, JOM 56 (10) (2004) 58-63.

[4] R.Z. Valiev, Nat. Mater. 3 (2004) 511.

[5] R.Z. Valiev, I.V. Alexandrov, Y.T. Zhu, T.C. Lowe, J. Mater. Res. 17 (2002) 5-8.

[6] J.Y. Huang, Y.T. Zhu, H. Jiang, T.C. Lowe, Acta. Mater. 49 (2001) 1497-1505.

[7] D.A. Hughes, N. Hansen, Phys. Rev. Lett. 8713 (2001), 135503 (1-4).

[8] K. Lu, J. Lu, J. Mater. Sci. Technol. 15 (1999) 193-197.

[9] K. Lu, J. Lu, Mater. Sci. Eng. A 38 (2004) 375-377.

[10] M. Umemoto, Mater. Trans. 44 (2003) 1900-1911.

[11] J.C. Villegas, L.L. Shaw, Acta Mater. 57 (2009) 5782-5795.

[12] K. Lu, N. Hansen, Scr. Mater. 60 (2009) 1033-1038.

[13] N.R. Tao, K. Lu, Scr. Mater. 60 (2009) 1039-1043.

[14] X. Wu, N. Tao, Y. Hong, B. Xu, J. Lu, K. Lu, Acta Mater. 50 (2002) 2075-2084

[15] Y.T. Zhu, J.Y. Huang, J. Gubicza, J. Mater. Res. 18 (2003) 1908-1917.

[16] K.Y. Zhu, A. Vassel, F. Brisset, K. Lu, J. Lu, Acta Mater. 52 (2004) 4101-4110.

[17] Y.J. Chen, Y.J. Li, J.C. Walmsley, Mater. Sci. Eng. 527 (2010) 789-796.

[18] M.R. Shankar, B.C. Rao, S. Lee, Acta Mater. 54 (2006) 3691-3700.

[19] R.Z. Valiev, I.P. Semenova, E. Jakushina, Mater. Sci. Forum 584-586 (2008) 49-54.

[20] X.C. Zhao, W.J. Fu, X.R. Yang, Scr. Mater. 59 (2008) 542-545.

[21] D.H. Shin, I. Kim, J. Kim, Y.S. Kim, S.L. Semiatin, Acta Mater. 51 (2003) 983-996.

[22] V.V. Stolyarov, R.Z. Valiev, Y.T. Zhu, Appl. Phys. Lett. 88 (2006) 041905.

[23] F.S. Sun, A. Zuniga, P. Rojas, E.J. Lavernia, Metall. Mater. Trans. A 37 A (2006) 2069-2078

[24] M.R. Drury, J.L. Ural, Tectonophysics 172 (1990) 235-253.

[25] B. Derby, M.F. Ashby, Scr. Metall. 21 (1987) 879-884. 
[26] M.R. Barnett, Acta Mater. 55 (2007) 3271-3279.

[27] M.R. Barnett, A.G. Beer, D. Atwell, A. Oudin, Scr. Mater. 51 (2004) 19-24.

[28] M.A. Meyers, Y.B. Xu, Q. Xue, M.T. Perez-Prado, T.R. McNelley, Acta Mater. 51 (2003) 1307-1325.

[29] I. Sabirov, Y. Estrin, M.R. Barnett, I. Timokhina, P.D. Hodgson, Acta Mater. 56 (2008) 2223-2230.
[30] J.A. Hines, K.S. Vecchio, S. Ahzi, Metall. Mater. Trans. A 29 (1998) 191-203.

[31] X. Zhang, H. Wang, J. Narayan, C.C. Koch, Acta Mater. 49 (2001) 1319-1326.

[32] M.A. Meyers, V.F. Nesterenko, J.C. LaSalvia, Q. Xue, Mater. Sci. Eng. A A317 (2001) 204-225.

[33] M.A. Meyers, G. Subhash, B.K. Kad, L. Prasad, Mech. Mater. 17 (1994) 175-190. 